\title{
Effect of Intramuscular Medetomidine Administration on Tear Flow in Rats
}

\author{
Teppei Kanda ${ }^{1,2, *}$, Yuka Mizoguchi ${ }^{2}$, Kayo Furumoto ${ }^{1,2}$, Yuki Shimizu ${ }^{1,2}$, Noritaka Maeta ${ }^{1,2}$ \\ and Toshinori Furukawa ${ }^{3}$ \\ 1 Faculty of Veterinary Medicine, Okayama University of Science, 1-3 Ikoino-oka, Imabari, \\ Ehime 794-8555, Japan \\ 2 Department of Comparative Animal Science, College of Life Science, Kurashiki University of Science and the \\ Arts, 2640 Nishinoura, Tsurajima-cho, Kurashiki, Okayama 712-8505, Japan \\ 3 Department of Animal Pharmaceutical Science, School of Pharmaceutical Science, Kyushu University of \\ Health and Welfare, 1714-1 Yoshino-cho, Nobeoka, Miyazaki 882-8508, Japan \\ * Correspondence: t-kanda@vet.ous.ac.jp
}

Received: 19 March 2020; Accepted: 10 April 2020; Published: 13 April 2020

\begin{abstract}
Medetomidine has been reported to decrease tear flow significantly in dogs, cats, and pigs when used as a sedative or analgesic; however, there are no such reports when it comes to rats. The present study aimed to investigate the effect of medetomidine on tear flow in rats. Medetomidine in doses of 50,100, or $200 \mu \mathrm{g} / \mathrm{kg}$ or a physiological saline solution as the control, were administered intramuscularly to male Slc:Wistar/ST rats. After the administration of medetomidine, tear flow in both eyes was measured using a phenol red thread tear test. The area under the curve (AUC) of phenol red thread test values from baseline to $8 \mathrm{~h}$ was calculated. Data were plotted against the dose of medetomidine and simple linear regression analysis was performed. The effect of the drug on phenol red thread test values was considered dose-related when linear analysis yielded a significant relationship. In all medetomidine-treated groups, tear flow decreased significantly in both eyes after administration, while no significant changes were observed in either eye in the control group. The AUC values from baseline to $8 \mathrm{~h}$ after administration in groups treated with 100 and $200 \mu \mathrm{g} / \mathrm{kg}$ of medetomidine were significantly lower in both the left and right eyes compared to the control group. The linear regression of the AUC values was significant for both eyes. Our results indicated that the intramuscular administration of medetomidine in rats decreased tear flow significantly in a dose-dependent manner.
\end{abstract}

Keywords: $\alpha_{2}$-adrenoceptor agonist; medetomidine; tear flow; phenol red thread test; rat

\section{Introduction}

Medetomidine, an $\alpha_{2}$-adrenoceptor agonist, is widely used as a sedative or analgesic in veterinary medicine [1-8]. In addition to medetomidine, other $\alpha_{2}$-adrenoceptor agonists such as detomidine [9-11], dexmedetomidine [1,12-14], xylazine $[4,7,9,14,15]$, and romifidine $[9,10,16-20]$ are also used clinically in many domestic species. Furthermore, some $\alpha_{2}$-adrenoceptor agonists, including medetomidine, are administered not only alone, but also in combination with other drugs, such as opioids, benzodiazepine, phenothiazine, and ketamine [3,5,6,8,21-27]. Although medetomidine and the other $\alpha_{2}$-adrenoceptor agonists used alone or in combination with other drugs have potent sedative or analgesic effects, they have been reported to significantly decrease tear flow in dogs [28-32], cats [33,34], horses [35,36], and pigs [37].

Tear fluids play an essential role in maintaining the immune system of the ocular surface and the metabolic processes of the cornea, which is an avascular tissue. Additionally, they maintain the 
smoothness of the optical surface by lubricating the cornea, conjunctiva, and nictitating membrane [38]. Therefore, an insufficient tear flow could cause pain or irritation on the ocular surface and could result in a vision disorder. A recent study also reported that tear fluid deficiency causes hypersensitivity in the rat cornea [39]. A small stimulus is likely to induce great irritation or pain even though there is no physical damage to the cornea. Apparently, it negatively affects the welfare of animals. Tear fluid deficiency should be the focus of current research, not only in order to protect ocular tissue and function, but also to relieve the irritation or pain.

In rats, a representative laboratory animal, medetomidine is administered both alone and in combination with other drugs [40-46]. However, the effect of medetomidine on tear flow has not been investigated, although clonidine, one of the $\alpha_{2}$-adrenoceptor agonists, was reported to decrease tear flow [47]. In horses, xylazine [48] and romifidine [36] were reported not to decrease tear flow, although detomidine was found to decrease it significantly [36]. This means that even if the administered agent is one of the $\alpha_{2}$-adrenoceptor agonists, its ability to decrease tear flow in a specific animal species varies with each drug. Therefore, the result of the study with clonidine might not necessarily be replicated in rats administered medetomidine. It is essential to know whether tear flow decreases in rats administered medetomidine to avoid inducing pain or irritation on the ocular surface, which could affect their welfare.

In the present study, we aimed to investigate the effect of medetomidine on tear flow in rats.

\section{Materials and Methods}

\subsection{Animals}

Male Slc:Wistar/ST rats (Rattus norvegicus) ( $\mathrm{n}=24$, aged 8-11 weeks; Japan SLC, Inc., Hamamatsu, Japan) weighing $325 \pm 23$ (mean \pm standard deviation (SD)) g were used. The animals were allowed to acclimatize for a week before treatment and were housed in groups of two to three animals in individually ventilated cages (NIKI SHOUJI Co., Tokyo, Japan) placed in one room. A 12:12 h light-dark cycle (light period, 8:00 a.m. to 20:00 p.m.) was maintained, room temperature was kept between 24 and $26^{\circ} \mathrm{C}$, and humidity was at $40-60 \%$. Water and a commercially pelleted diet (CE-2; CLEA Japan, Inc., Tokyo, Japan) were provided ad libitum. After the intramuscular administration of medetomidine or saline, a single rat was placed in an individually ventilated cage on the laboratory table of the experimental room. The rat stayed there for $24 \mathrm{~h}$ between measurements. Wood shavings (CL-4161; CLEA Japan, Inc., Tokyo, Japan) were used as bedding material in all cages. Six rats were assigned randomly to any of the four treatment groups and were not blinded. All procedures performed were approved by the Animal Care and Use Committee of Kurashiki University of Science and the Arts (approval number, 25-12).

\subsection{Drug Treatment}

Medetomidine (1000 $\mu \mathrm{g} / \mathrm{mL}$, Domitor; Nippon Zenyaku Kogyo Co., Ltd., Fukushima, Japan) in doses of 50,100, or $200 \mu \mathrm{g} / \mathrm{kg}$, or a physiological saline solution $(0.2 \mathrm{~mL} / \mathrm{kg})$ as the control, were administered intramuscularly to the rats. According to the treatment received, groups were named MED50, MED100, MED200, and control group, respectively. The drug solution was injected into the caudal part of the left thigh using a micro syringe (1/2 mL BD Lo-Dose Insulin Syringe $29 \mathrm{G} \times$ 1/2 inch; BD, Franklin Lakes, NJ, USA) at 10:00 a.m.

\subsection{Measurement}

Tear flow was measured using a phenol red thread tear test (Zone-Quick; AYUMI Pharmaceutical Corporation, Tokyo, Japan) in both eyes [49,50]. The $3 \mathrm{~mm}$ tips of threads were placed on the medial canthus for $15 \mathrm{~s}$. The length of the moistened area from the edge was measured as the phenol red thread test (PRTT) value. Tear flow was measured approximately 1 min before and $0.25,0.5,1,2,3,4,5$, $6,7,8$, and $24 \mathrm{~h}$ after medetomidine administration. 


\subsection{Observation}

The state of the ocular surface, including corneal opacity, was observed grossly, together with recording the measurements of PRTT values. The presence of any significant side effects was monitored throughout the experiments.

\subsection{Statistical Analysis}

The Wilcoxon matched-pairs signed-rank test was used to examine the differences in PRTT values between the left and right eyes at each time point for each treatment. The time effect on each treatment was evaluated using the Friedman test for repeated measures. When a significant change was found, Dunn's multiple comparison test was used to compare the mean value at each time point with the baseline value in each treatment. The area under the curve (AUC) of PRTT values from baseline to $8 \mathrm{~h}$ was calculated. Data were plotted against the dose of medetomidine and simple linear regression analysis was performed. The effect of a drug on PRTT values was considered dose-related when linear analysis yielded a significant relationship. The Kruskal-Wallis test was used for comparison of mean AUC values. When a significant change was found, Dunn's multiple comparison test was used to compare the mean AUC values between treatments. PRTT and AUC values were reported as mean \pm standard error of the mean (SEM) and mean \pm standard deviation (SD), respectively. Mean values of age and body weight in each group were compared using the one-way analysis of variance (ANOVA). When a significant difference was found, Tukey's multiple comparison test was used to compare the mean values between groups. All statistical analyses were performed using GraphPad Prism 8 (GraphPad Software, San Diego, CA, USA). A p-value < 0.05 was considered statistically significant.

\section{Results}

There were no statistical differences in age and body weight between the groups.

The baseline PRTT values in the left and right eyes were $13.0 \pm 0.5$ and $14.2 \pm 0.7 \mathrm{~mm} / 15 \mathrm{~s}$ respectively, in the control group, $15.0 \pm 0.7$ and $14.5 \pm 0.8 \mathrm{~mm} / 15 \mathrm{~s}$ respectively, in MED50, $14.0 \pm 1.0$ and $13.5 \pm 0.9 \mathrm{~mm} / 15 \mathrm{~s}$ respectively, in MED100, and $15.5 \pm 1.1$ and $16.0 \pm 1.0 \mathrm{~mm} / 15 \mathrm{~s}$ respectively, in MED200. There were no differences in PRTT values between the left and right eyes in each time point for all groups. In the control group, there were no significant changes in either eye (Figure 1). In MED50, PRTT values decreased significantly 0.25-4 h $(3.5 \pm 0.5,4.0 \pm 0.3,5.2 \pm 0.9,6.5 \pm 1.1$, $6.3 \pm 1.4$, and $6.0 \pm 0.8 \mathrm{~mm} / 15 \mathrm{~s}$, respectively) and $0.25-2 \mathrm{~h}(4.8 \pm 0.7,4.3 \pm 0.3,4.2 \pm 0.5$, and $7.0 \pm$ $1.1 \mathrm{~mm} / 15 \mathrm{~s}$, respectively) after the intramuscular administration of medetomidine in the left and right eye, respectively. These decreases were followed by a gradual recovery to the baseline value. In MED100, significant decreases in PRTT values were observed 0.25-3 h $(4.2 \pm 1.0,3.7 \pm 0.3,4.0 \pm$ $0.4,4.0 \pm 0.5$, and $4.2 \pm 0.3 \mathrm{~mm} / 15 \mathrm{~s}$, respectively) and $0.25-2 \mathrm{~h}(3.7 \pm 0.3,3.5 \pm 0.3,3.8 \pm 0.2$, and $4.3 \pm 0.7 \mathrm{~mm} / 15 \mathrm{~s}$, respectively) after the administration of medetomidine in the left and right eye, respectively. In MED200, significant decreases in PRTT values were observed 0.25-5 (4.8 $\pm 1.2,3.7 \pm$ $0.3,4.5 \pm 0.5,4.3 \pm 0.3,4.0 \pm 0.5,4.3 \pm 0.6$, and $42 . \pm 0.6 \mathrm{~mm} / 15 \mathrm{~s}$, respectively) and $0.25-4 \mathrm{~h}(4.0 \pm 0.4$, $3.0 \pm 0.0,3.7 \pm 0.2,4.2 \pm 0.5,4.0 \pm 0.3$, and $4.2 \pm 0.8 \mathrm{~mm} / 15 \mathrm{~s}$, respectively) after the administration of medetomidine in the left and right eye, respectively. PRTT values remained at lower levels for longer in MED200 than they did in MED50 and MED100. Twenty-four hours after the intramuscular administration of medetomidine, the PRTT values of both eyes returned to the baseline levels in all treatment groups. 

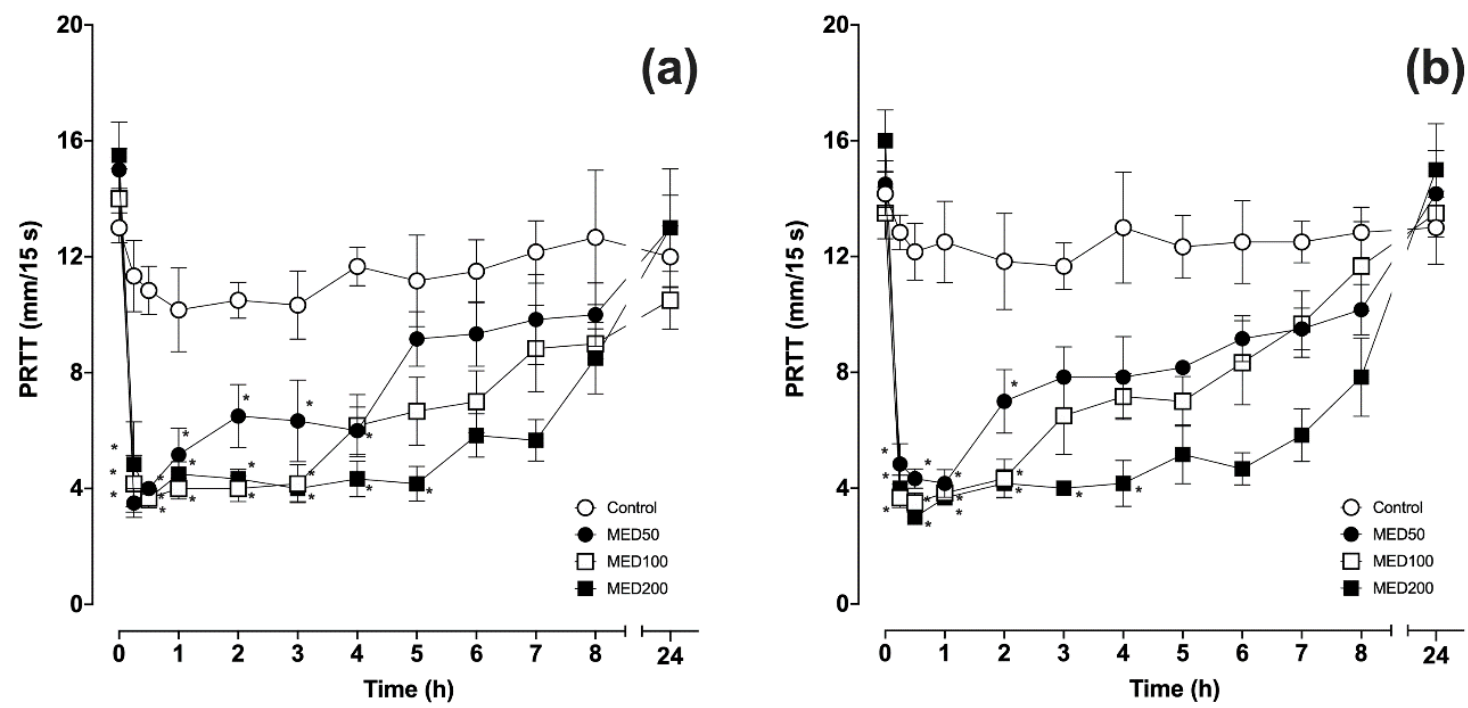

Figure 1. Mean \pm standard error of the mean (SEM) of phenol red thread test (PRTT) values in the left (a) and right $(\mathbf{b})$ eyes before and after intramuscular administration of medetomidine $(n=6) .{ }^{*} p<0.05$ compared with the baseline value.

Throughout the experiments, in all groups, no gross changes were observed in the ocular surfaces, including the cornea. In addition, no significant side effects related to the $\alpha_{2}$-adrenoceptor agonists, such as severe cardiopulmonary depressions or neurological abnormalities, were observed throughout the experiments.

The AUC values from baseline to $8 \mathrm{~h}$ after administration in MED100 and MED200 were significantly lower in both the left and right eyes compared to the control group. The linear regression of the AUC values was significant for both eyes (Figure 2).
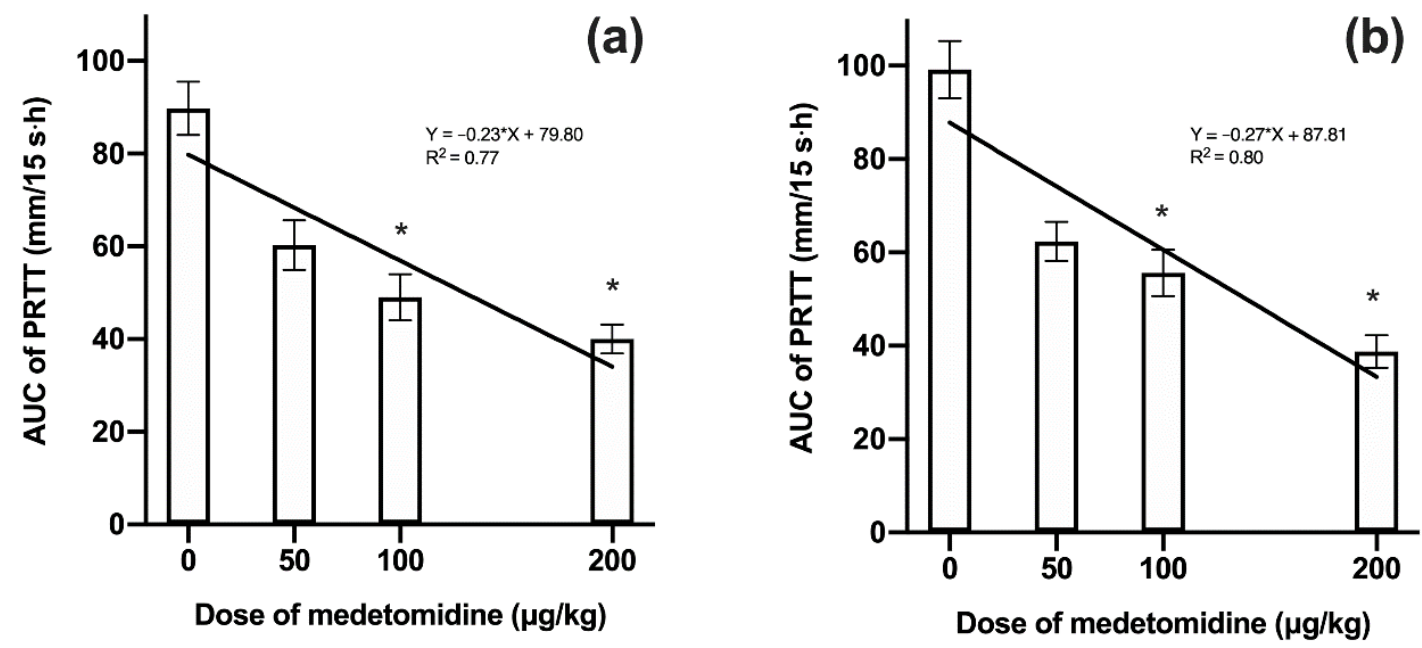

Figure 2. Mean \pm standard deviation (SD) of area under the curve (AUC) values in the left (a) and right (b) eyes during the $8 \mathrm{~h}$ period after the intramuscular administration of various doses of medetomidine $(\mathrm{n}=6)$. ${ }^{*} p<0.05$ compared with the control group.

\section{Discussion}

The results of the present study indicated that the intramuscular administration of medetomidine significantly decreased tear flows in rats. The reference range of PRTT values in different rat strains, or rats in general for that matter, has not been reported. In previous studies, the control PRTT values in Sprague-Dawley rats were reported as $10 \pm 1.0 \mathrm{~mm} / 15 \mathrm{~s}$ for first-time measurements and 10.8 $\pm 1.9 \mathrm{~mm} / 15 \mathrm{~s}$ for second-time measurements (8 weeks after the first measurements and vehicle 
administration) by Hegarty et al. [49], or approximately $13 \mathrm{~mm} / 15 \mathrm{~s}$ by Nakamura et al. (shown in a graph without values) [50]. In this study, similar PRTT values were obtained for the control group, although the strain was different. Based on these facts, it could be suggested that the decrease in tear flow after intramuscular administration of medetomidine was significantly below the physiological range for rats.

The higher the dose of medetomidine, the longer the tear flow decrease lasted compared to the baseline value, while the lowest tear flow value was similar in all groups treated with medetomidine. AUC values from baseline to $8 \mathrm{~h}$ after administration indicated that the decrease of tear flow in rat was dose-dependent. Therefore, it is advisable to reduce the dose of medetomidine to avoid severe decrease in tear flow due to the high doses.

It was reported that $\alpha_{2}$-adrenoceptor agonists, including medetomidine, decrease tear flow in many species, such as dogs, cats, horses, and pigs [28-37]. The mechanism through which $\alpha_{2}$-adrenoceptor agonists decrease tear flow is not yet completely clarified, although local or systemic involvement of an $\alpha_{2}$-adrenoceptor was suggested in previous studies [28,31,32,34,36]. Some mechanisms through which $\alpha_{2}$-adrenoceptor agonists, including medetomidine, possibly decrease tear flow have been previously reported $[31,32,34,36]$. Among these, the neurophysiological mechanisms and hemodynamic change involved with the $\alpha_{2}$-adrenoceptor have been discussed as the most likely reasons [32,36]. Leonardi suggested that postsynaptic activation of $\alpha_{2}$-adrenoceptors in the central nervous system due to $\alpha_{2}$-adrenoceptor agonists might have decreased basal tear production in previous studies on dogs and horses [31,36]. The fact that atipamezole, an $\alpha_{2}$-adrenoceptor antagonist, recovered or attenuated the decrease in tear flow induced by $\alpha_{2}$-adrenoceptor agonists indirectly supports these suggestions [28,31]. Although adrenergic nerve fibers innervate the lacrimal glands in mice and dogs [51,52], this has not been identified in rats. Medetomidine induces systemic vasoconstriction, lower heart rate, and a decrease in cardiac output in mammals [53,54]. Consequently, perfusion of the lacrimal glands should decrease after medetomidine administration. Such lowered perfusion of lacrimal glands has been suggested to be responsible for $\alpha_{2}$-adrenoceptor agonist-induced decrease in tear flow [31,34,36]. As another possible mechanism, alteration of metabolism at the lacrimal gland cellular level through the $\alpha_{2}$-adrenoceptor has been proposed to decrease tear production [32]. At present, although the existence or function of $\alpha_{1}$-adrenoceptor in the lacrimal gland in rats or mice has been reported, there have been no reports regarding the $\alpha_{2}$-adrenoceptor in the lacrimal glands of any species $[55,56]$. Furthermore, it was also suggested that increased antinociception modulated by $\alpha_{2}$-adrenoceptor decreases reflex tear secretion [32].

In this study, no significant gross corneal lesions were observed in rats even though tear flow decreased significantly. Therefore, we concluded that the medetomidine-induced decrease in tear flow did not cause any gross corneal opacity lesions in rats at the tested doses of medetomidine.

There were several limitations in this study. We could not discuss the relationship between the effects of medetomidine on the central nervous system, such as sedation or changes in autonomic tone, and decrease in tear flow, because the degree and duration of sedation and physiological parameters, including heart rate and respiratory rate, were not measured. Additionally, we did not measure the PRTT values between 8 to $24 \mathrm{~h}$ after medetomidine administration; thus, we could not determine how long the decrease in PRTT persisted.

\section{Conclusions}

We concluded that the intramuscular administration of medetomidine led to a dose-dependent and significant decrease in tear flow in rats, measured by PRTT. Although the decrease in tear flow induced by medetomidine did not cause a gross corneal lesion within $24 \mathrm{~h}$ after administration, the ocular surface should be treated to protect ocular health and the welfare of the rats.

Author Contributions: Conceptualization, T.K. and Y.M.; methodology, T.K. and T.F.; validation, T.K., Y.M., and T.F.; formal analysis, K.F.; investigation, T.K., Y.M., Y.S., and N.M.; resources, T.K.; data curation, Y.M., Y.S., and N.M.; writing - original draft preparation, T.K. and Y.M.; writing—review and editing, T.K.; visualization, K.F.; 
supervision, T.K.; project administration, T.K. All authors have read and agreed to the published version of the manuscript.

Funding: This research received no external funding.

Conflicts of Interest: The authors declare no conflict of interest.

\section{References}

1. Granholm, M.; McKusick, B.C.; Westerholm, F.C.; Aspegrén, J.C. Evaluation of the clinical efficacy and safety of dexmedetomidine or medetomidine in cats and their reversal with atipamezole. Vet. Anaesth. Analg. 2006, 33, 214-223. [CrossRef] [PubMed]

2. Pollock, C.G.; Schumacher, J.; Orosz, S.E.; Ramsay, E.C. Sedative effects of medetomidine in pigeons (Columba livia). J. Avian Med. Surg. 2001, 15, 95-100. [CrossRef]

3. Hayashi, K.; Nishimura, R.; Yamaki, A.; Kim, H.; Matsunaga, S.; Sasaki, N.; Takeuchi, A. Comparison of sedative effects induced by medetomidine, medetomidine-midazolam and medetomidine-butorphanol in dogs. J. Vet. Med. Sci. 1994, 56, 951-956. [CrossRef] [PubMed]

4. Rioja, E.; Kerr, C.L.; Enouri, S.S.; McDonell, W.N. Sedative and cardiopulmonary effects of medetomidine hydrochloride and xylazine hydrochloride and their reversal with atipamezole hydrochloride in calves. Am. J. Vet. Res. 2008, 69, 319-329. [CrossRef]

5. Lee, J.Y.; Jee, H.C.; Jeong, S.M.; Park, C.S.; Kim, M.C. Comparison of anaesthetic and cardiorespiratory effects of xylazine or medetomidine in combination with tiletamine/zolazepam in pigs. Vet. Rec. 2010, 167, $245-249$. [CrossRef]

6. Girard, N.M.; Leece, E.A.; Cardwell, J.; Adams, V.J.; Brearley, J.C. The sedative effects of low-dose medetomidine and butorphanol alone and in combination intravenously in dogs. Vet. Anaesth. Analg. 2010, 37, 1-6. [CrossRef]

7. Bryant, C.E.; England, G.C.; Clarke, K.W. Comparison of the sedative effects of medetomidine and xylazine in horses. Vet. Rec. 1991, 129, 421-423. [CrossRef]

8. Jalanka, H.H. Medetomidine- and medetomidine-ketamine-induced immobilization in blue foxes (Alopex lagopus) and its reversal by atipamezole. Acta Vet. Scand. 1990, 31, 63-71.

9. England, G.C.W.; Clarke, K.W.; Goossens, L. A comparison of the sedative effects of three $\alpha 2$-adrenoceptor agonists (romifidine, detomidine and xylazine) in the horse. J. Vet. Pharmacol. Ther. 1992, 15, 194-201. [CrossRef]

10. Rohrbach, H.; Korpivaara, T.; Schatzmann, U.; Spadavecchia, C. Comparison of the effects of the alpha-2 agonists detomidine, romifidine and xylazine on nociceptive withdrawal reflex and temporal summation in horses. Vet. Anaesth. Analg. 2009, 36, 384-395. [CrossRef]

11. Hopfensperger, M.J.; Messenger, K.M.; Papich, M.G.; Sherman, B.L. The use of oral transmucosal detomidine hydrochloride gel to facilitate handling in dogs. J. Vet. Behav. 2013, 8, 114-123. [CrossRef]

12. Bloor, B.C.; Frankland, M.; Alper, G.; Raybould, D.; Weitz, J.; Shurtliff, M. Hemodynamic and sedative effects of dexmedetomidine in dog. J. Pharmacol. Exp. Ther. 1992, 263, 690-697. [PubMed]

13. Cagnardi, P.; Villa, R.; Ravasio, G.; Lucatello, L.; Di Cesare, F.; Capolongo, F.; Boccardo, A.; Pravettoni, D. Pharmacokinetics and sedative effects of dexmedetomidine in dairy calves. N. Z. Vet. J. 2017, 65, 14-18. [CrossRef] [PubMed]

14. Samimi, A.S.; Molaei, M.M.; Azari, O.; Ebrahimpour, F. Comparative evaluation of sedative and clinical effects of dexmedetomidine and xylazine in dromedary calves (Camelus dromedarius). Vet. Anaesth. Analg. 2020, 47, 224-228. [CrossRef] [PubMed]

15. Ede, T.; von Keyserlingk, M.A.G.; Weary, D.M. Efficacy of xylazine in neonatal calves via different routes of administration. Vet. J. 2019, 247, 57-60. [CrossRef]

16. Figueiredo, J.; Muir, W.; Smith, J.; Wolfrom, G. Sedative and analgesic effects of romifidine in horses. Int. J. Appl. Res. Vet. Med. 2005, 3, 249-258.

17. Selmi, A.L.; Barbudo-Selmi, G.R.; Mendes, G.M.; Figueiredo, J.P.; Lins, B.T. Sedative, analgesic and cardiorespiratory effects of romifidine in cats. Vet. Anaesth. Analg. 2004, 31, 195-206. [CrossRef]

18. Navarrete, R.; Domínguez, J.M.; del Mar Granados, M.; Morgaz, J.; Fernández, A.; Gómez-Villamandos, R.J. Sedative effects of three doses of romifidine in comparison with medetomidine in cats. Vet. Anaesth. Analg. 2011, 38, 178-185. [CrossRef] 
19. England, G.C.W.; Flack, T.E.; Hollingworth, E.; Hammond, R. Sedative effects of romifidine in the dog. J. Small Anim. Pract. 1996, 37, 19-25. [CrossRef]

20. Belda, E.; Laredo, F.G.; Escobar, M.; Soler, M.; Lucas, X.; Agut, A. Sedative and cardiorespiratory effects of three doses of romifidine in comparison with medetomidine in five cats. Vet. Rec. 2008, 162, 82-87. [CrossRef]

21. Zeiler, G.E.; Dzikiti, B.T.; Fosgate, G.T.; Stegmann, F.G.; Venter, F.J.; Rioja, E. Anaesthetic, analgesic and cardiorespiratory effects of intramuscular medetomidine-ketamine combination alone or with morphine or tramadol for orchiectomy in cats. Vet. Anaesth. Analg. 2014, 41, 411-420. [CrossRef] [PubMed]

22. Harrison, K.A.; Robertson, S.A.; Levy, J.K.; Isaza, N.M. Evaluation of medetomidine, ketamine and buprenorphine for neutering feral cats. J. Feline Med. Surg. 2011, 13, 896-902. [CrossRef] [PubMed]

23. Grint, N.J.; Alderson, B.; Dugdale, A.H.A. A comparison of acepromazine-buprenorphine and medetomidine-buprenorphine for preanesthetic medication of dogs. J. Am. Vet. Med. Assoc. 2010, 237, 1431-1437. [CrossRef] [PubMed]

24. Curro, T.G.; Okeson, D.; Zimmerman, D.; Armstrong, D.L.; Simmons, L.G. Xylazine-midazolam-ketamine versus medetomidine-midazolam-ketamine anesthesia in captive siberian tigers (Panthera Tigris Altaica). J. Zoo Wildl. Med. 2004, 35, 320-327. [CrossRef]

25. Miller, M.; Weber, M.; Neiffer, D.; Mangold, B.; Fontenot, D.; Stetter, M. Anesthetic induction of captive tigers (Panthera tigris) using a medetomidine-ketamine combination. J. Zoo Wildl. Med. 2003, 34, 307-308. [CrossRef]

26. Shilo, Y.; Lapid, R.; King, R.; Bdolah-Abram, T.; Epstein, A. Immobilization of red fox (Vulpes vulpes) with medetomidine-ketamine or medetomidine-midazolam and antagonism with atipamezole. J. Zoo Wildl. Med. 2010, 41, 28-34. [CrossRef]

27. Pratt, S.; Cunneen, A.; Perkins, N.; Farry, T.; Kidd, L.; McEwen, M.; Rainger, J.; Truchetti, G.; Goodwin, W. Total intravenous anaesthesia with ketamine, medetomidine and guaifenesin compared with ketamine, medetomidine and midazolam in young horses anaesthetised for computerised tomography. Equine Vet. J. 2019, 51, 510-516. [CrossRef]

28. Sanchez, R.F.; Mellor, D.; Mould, J. Effects of medetomidine and medetomidine-butorphanol combination on Schirmer tear test 1 readings in dogs. Vet. Ophthalmol. 2006, 9, 33-37. [CrossRef]

29. Kanda, T.; Ishihara, S.; Oka, M.; Sako, K.; Sato, Y.; Maeta, N.; Tamura, K.; Furumoto, K.; Furukawa, T. Temporal effects of intramuscular administration of medetomidine hydrochloride or xylazine hydrochloride to healthy dogs on tear flow measured by use of a schirmer tear test I. Am. J. Vet. Res. 2016, 77, 346-350. [CrossRef]

30. Abdelhakiem, M.A.H.; Elmeligy, E.; Al-lethie, A. Effect of xylazine $\mathrm{HCl}$ and/or Ketamine $\mathrm{HCl}$ on the Tear production in clinically healthy dogs. Adv. Anim. Vet. Sci. 2019, 7, 1015-1020. [CrossRef]

31. Leonardi, F.; Costa, G.L.; Stagnoli, A.; Zubin, E.; Boschi, P.; Sabbioni, A.; Simonazzi, B. The effect of intramuscular dexmedetomidine-butorphanol combination on tear production in dogs. Can. Vet. J. = La Rev. Vet. Can. 2019, 60, 55-59.

32. Dodam, J.R.; Branson, K.R.; Martin, D.D. Effects of intramuscular sedative and opioid combinations on tear production in dogs. Vet. Ophthalmol. 1998, 1, 57-59. [CrossRef]

33. Kanda, T.; Shimizu, Y.; Hanazono, C.; Maki, S.; Maeta, N.; Itoi, T.; Furumoto, K.; Okamura, Y.; Itoh, Y.; Furukawa, T. Effect of intramuscular administration of medetomidine and xylazine on tear flow measured by the Schirmer tear test I in healthy cats. J. Feline Med. Surg. 2018, 21, 788-792. [CrossRef]

34. Ghaffari, M.S.; Malmasi, A.; Bokaie, S. Effect of acepromazine or xylazine on tear production as measured by Schirmer tear test in normal cats. Vet. Ophthalmol. 2010, 13,1-3. [CrossRef]

35. Selk Ghaffari, M.; Brooks, D.E.; Sabzevari, A.; Ghamsari, S.M.; Mansoor Lakooraj, H.; Shad, H. Effects of intravenous detomidine on schirmer tear test results in clinically normal horses. J. Equine Vet. Sci. 2017, 55, 97-99. [CrossRef]

36. Leonardi, F.; Costa, G.L.; Dubau, M.; Sabbioni, A.; Simonazzi, B.; Angelone, M. Effects of intravenous romifidine, detomidine, detomidine combined with butorphanol, and xylazine on tear production in horses. Equine Vet. Educ. 2018. [CrossRef]

37. Kanda, T.; Kajiyama, A.; Morimitsu, W.; Nishino, Y.; Oishi, Y.; Shimizu, Y.; Maeta, N.; Furumoto, K.; Itoh, Y.; Furukawa, T. Effect of medetomidine on tear flow measured by Schirmer tear test I in normal pigs. J. Vet. Med. Sci. 2019, 81, 538-540. [CrossRef] 
38. Moore, C.P. Disease and surgery of the lacrimal secretory system. In Veterinary ophthalmology; Gelatt, K.N., Ed.; Lippincott Williams \& Wilkins: Baltimore, MD, USA, 1999; pp. 583-607.

39. Meng, I.D.; Barton, S.T.; Mecum, N.E.; Kurose, M. Corneal sensitivity following lacrimal gland excision in the rat. Investig. Ophthalmol. Vis. Sci. 2015, 56, 3347-3354. [CrossRef]

40. Rahmanian-Schwarz, A.; Held, M.; Knoeller, T.; Amr, A.; Schaller, H.-E.; Jaminet, P. The effect of repetitive intraperitoneal anesthesia by application of fentanyl-medetomidine and midazolam in laboratory rats. J. Investig. Surg. 2012, 25, 123-126. [CrossRef]

41. Bellini, L.; Banzato, T.; Contiero, B.; Zotti, A. Evaluation of three medetomidine-based protocols for chemical restraint and sedation for non-painful procedures in companion rats (Rattus norvegicus). Vet. J. 2014, 200, 456-458. [CrossRef]

42. Tsukamoto, A.; Niino, N.; Sakamoto, M.; Ohtani, R.; Inomata, T. The validity of anesthetic protocols for the surgical procedure of castration in rats. Exp. Anim. 2018, 67, 329-336. [CrossRef]

43. Weber, R.; Ramos-Cabrer, P.; Wiedermann, D.; Van Camp, N.; Hoehn, M. A fully noninvasive and robust experimental protocol for longitudinal fMRI studies in the rat. Neuroimage 2006, 29, 1303-1310. [CrossRef]

44. Hedenqvist, P.; Roughan, J.V.; Flecknell, P.A. Sufentanil and medetomidine anaesthesia in the rat and its reversal with atipamezole and butorphanol. Lab. Anim. 2000, 34, 244-251. [CrossRef]

45. Hu, C.; Flecknell, P.A.; Liles, J.H. Fentanyl and medetomidine anaesthesia in the rat and its reversal using atipamazole and either nalbuphine or butorphanol. Lab. Anim. 1992, 26, 15-22. [CrossRef]

46. Pawela, C.P.; Biswal, B.B.; Hudetz, A.G.; Schulte, M.L.; Li, R.; Jones, S.R.; Cho, Y.R.; Matloub, H.S.; Hyde, J.S. A protocol for use of medetomidine anesthesia in rats for extended studies using task-induced BOLD contrast and resting-state functional connectivity. Neuroimage 2009, 46, 1137-1147. [CrossRef]

47. Weisse, I.; Hoefke, W.; Greenberg, S.; Gaida, W.; Stötzer, H.; Kreuzer, H. Ophthalmological and pharmacological studies after administration of clonidine in rats. Arch. Toxicol. 1978, 41, 89-98. [CrossRef]

48. Brightman, A.H.; Manning, J.P.; Benson, G.J.; Musselman, E.E. Decreased tear production associated with general anesthesia in the horse. J. Am. Vet. Med. Assoc. 1983, 182, 243-244.

49. Hegarty, D.M.; David, L.L.; Aicher, S.A. Lacrimal gland denervation alters tear protein composition and impairs ipsilateral eye closures and corneal nociception. Investig. Ophthalmol. Vis. Sci. 2018, 59, 5217-5224. [CrossRef]

50. Nakamura, S.; Kimura, Y.; Mori, D.; Imada, T.; Izuta, Y.; Shibuya, M.; Sakaguchi, H.; Oonishi, E.; Okada, N.; Matsumoto, K.; et al. Restoration of tear secretion in a murine dry eye model by oral administration of palmitoleic acid. Nutrients 2017, 9, 364. [CrossRef]

51. Powell, C.C.; Martin, C.L. Distribution of cholinergic and adrenergic nerve fibers in the lacrimal glands of dogs. Am. J. Vet. Res. 1989, 50, 2084-2088.

52. Ding, C.; Walcott, B.; Keyser, K.T. Sympathetic neural control of the mouse lacrimal gland. Investig. Ophthalmol. Vis. Sci. 2003, 44, 1513-1520. [CrossRef]

53. Pypendop, B.H.; Verstegen, J.P. Hemodynamic Effects of Medetomidine in the Dog: A Dose Titration Study. Vet. Surg. 1998, 27, 612-622. [CrossRef]

54. Lamont, L.A.; Bulmer, B.J.; Grimm, K.A.; Tranquilli, W.J.; Sisson, D.D. Cardiopulmonary evaluation of the use of medetomidine hydrochloride in cats. Am. J. Vet. Res. 2001, 62, 1745-1762. [CrossRef]

55. Ding, C.; Walcott, B.; Keyser, K.T. The $\alpha 1$ - and $\beta 1$-Adrenergic Modulation of Lacrimal Gland Function in the Mouse. Investig. Ophthalmol. Vis. Sci. 2007, 48, 1504-1510. [CrossRef]

56. Ikeda-Kurosawa, C.; Higashio, H.; Nakano, M.; Okubo, M.; Satoh, Y.; Kurosaka, D.; Saino, T. $\alpha 1$-Adrenoceptors relate Ca2+ modulation and protein secretions in rat lacrimal gland. Biomed. Res. 2015, 36, 357-369. [CrossRef]

(C) 2020 by the authors. Licensee MDPI, Basel, Switzerland. This article is an open access article distributed under the terms and conditions of the Creative Commons Attribution (CC BY) license (http://creativecommons.org/licenses/by/4.0/). 